\title{
The Millon Behavioral Medicine Diagnostic: Profiles of Dementia and Depression Chris Scoggins, ${ }^{a}$ Ciera Scott,${ }^{a}$ Lee Hyer ${ }^{b, c}$
}

Dementia (or cognitive decline) either results in or causes changes in personality and treatment patterns as the person declines. From a sample of older adults with memory complaints who have varying problems of dementia, depression or both, we address two issues: (1) we provide a personality, stress moderator and treatment prognostic profile of older adults with and without dementia; and (2) we consider the question of the added influence of depression related to these variables. For question 1, older subjects $(\mathrm{N}=112)$ were disaggregated by dementia and non-dementia status; for question 2, the older adults $(\mathrm{N}=62)$ were further separated into those with a dementia, those who are depressed, and those with both dementia and depression. Patients were interviewed and self-report scales were given to all subjects. All patients had a caregiver. Cognitive and personality styles, treatment and stress markers, and Axis I variables, as well as background and adjustment, were measured. For dementia/nondementia groups, results show that the dementia group was more detached, had more problems with depression and cognitive dysfunction, and showed less concerns about Informational Fragility. Of the three groups, the combined and dementia groups had the most problems, including more fixed personality features, more psychiatric problems, more stress moderators and more problematic treatment prognostics. We also show profiles of treatment prognostics and stress moderators of each personality type for a dementia, depression and dementia/depression. We highlight the importance of depression at later life whether with or without a dementia.

Keywords: Dementia, depression, personality

\section{Introduction}

Dementia accrues dramatically at late life, building to some estimates to $50 \%$ over age 85 (Jack et al., 2011). Alzheimer's disease (AD) is the most common cause of dementia. More broadly, almost one in every four elderly people suffers from serious cognitive decline, and a sizable proportion of these people become demented (Hollon et al., 2005). Even if the older person does not have such a severe degenerative disease, the insults of normal cognitive aging, especially mild cognitive impairment (MCI), can lead to problems in adjustment and life quality (Jeste et al., 1999).

Importantly, changes in personality, either before or after obvious signs of cognitive problems, appears in most dementias. Insults to the brain, as well as environmental changes, can alter a person's predominant personality traits; increasing, decreasing, or neutralizing them. As the disease progresses, personality styles become exacerbated or the person simply shuts down in order to defend the self (Hyer \& Intrieri, 2006). This accommodation is also no doubt made more difficult when cognitive problems are accompanied by depression or anxiety, both common emotional problems in later life (Blazer, 2003).

The issue, then, of dementia and its correlative problem of depression as these relate to personality and general stress and treatment concerns is assessed here. Specifically, we address two issues related to cognitive decline and emotion in older adults with memory problems. First, we address personality profile of older adults with and without a dementia who have memory complaints. In this context we also consider stress (stress moderators) and treatment (treatment prognostics) for these groups in the context of treatment. Second, we consider the question of the influence of depression in this mix; do older adults with a dementia and depression have more problems in stress and treatment, as well as other markers. We also provide a profile of treatment and stress markers for each personality style, given dementia, depression, dementia/depression, and even normal status.

Personality is an important but limitedly understood variable in late life and certainly in the context of dementia. Some studies have found little evidence for the influence of personality (Abrams \& Horowitz, 1996), while others suggest that personality may be helpful in understanding and predicting dementia-related behavior changes (Finkel, 1998). In an earlier study, Catterjee, Strauss, Smyth, and Whitehouse (1992) found a correlation between premorbid personality characteristics and subsequent psychiatric symptoms in dementia. Patients exhibiting symptoms of depressed mood were rated as premorbidly more neurotic or less emotionally stable. Patients with paranoid delusions were rated as having been more hostile prior to the onset of dementia. Patients with hallucinations were reported as pre-morbidly more open, particularly in the facets of fantasy and aesthetics. Gould and Hyer (2005) have suggested that patients with dementia have premorbid personality traits (e.g., neuroticism) that impact on their behavior profile during the course of the illness. They assessed the influence of premorbid personality on the expression of behavioral disturbances among individuals with dementia. A total of 68 outpatients with a diagnosis of dementia were assessed for current cognitive functioning, premorbid personality traits, and new behavioral disturbances since dementia onset. The results of this study showed evidence for the influence of personality on the expression of both irritability and withdrawal. Specifically, increased withdrawal and irritability after dementia onset were associated with an inhibited premorbid personality style. In addition, a

a. Mercer University, GA

b. Georgia Neurological Institute, GA

c. Mercer University School of Medicine, GA 
premorbid independent personality style was associated with less withdrawal. Results suggested that personality may be a value-added construct in the explanation of problem behaviors for those who are dementing. Segal, Coolidge, and Rosowsky (2006) have also suggested that the influence of personality in a dementing process can be substantial.

Cognitive problems certainly influence more than personality. Neuropsychiatric symptoms, such as anxiety and depression, are frequently found in patients with cognitive decline and dementia (Baldwin et al., 2003; Charlson \& Peterson, 2002; Goldman et al., 1999; Charney et al., 2003; Harman et al., 2002; Uebelacker et al., 2006; Blazer et al., 2005; Alexopoulos et al., 2005; Lyketsos \& Olin, 2002; Lyketsos et al., 2003; de Vasconcelos et al., 2007; Tiemeier, 2003; Alexopoulos et al., 1997; de Leeuw et al., 2001). For example, research by Lopez et al. (2003) on anxiety symptoms in elderly diagnosed with Alzheimer's Disease (AD) showed that anxiety is more common among patients with severe cognitive deficits than in those with mild or moderate deficits. However, two other studies showed an increase in anxiety as cognitive deficits develop from mild to moderate and a decline in anxiety as $\mathrm{AD}$ progresses into severe cognitive deficits (Breteler et al., 1994; Kalayam \& Alexopoulos, 1999).

Other research suggests that depression becomes less common as dementia and cognitive decline become more severe. Some have found depressive symptoms were not related to cognitive status in AD (Alexopoulos et al., 2000; Arve et al., 1999), while other studies found depression to be common in the early phase of $\mathrm{AD}$, and then decreased over time (Blazer et al., 2005; Lopez et al., 2003; Sneed et al., 2007; Potter et al., 2004; Story et al., 2008). In addition, when one becomes depressed in a dementia, evidence is that the depression is different from usual depression, that the course of illness can be worse, and that treatment for these patients is problematic (Banerjee et al., 2011). The data then are sparse and somewhat confusing.

Comorbid anxiety and depressive symptoms are related to cognitive decline and follow an undulating pattern of prevalence; affect symptoms increase in prevalence and then decrease as cognitive performance declines, especially when cognitive functioning is severely impaired. In general, there seems to be an increase in symptoms as cognitive performance levels drop from average to moderate and a decrease in symptoms as cognitive functioning declines to the level of poor cognitive functioning or elderly people are diagnosed with AD. This decline was also found in earlier research (Blazer et al., 2005; Lopez et al., 2003; Story et al., 2008), which investigated depressive symptoms in $\mathrm{AD}$ patients.

The extent to which these affect problems influence treatment concerns is unknown. Less studied, then, is the influence of stress moderators and treatment prognostics, as well as life style markers, in cognitive disorders, such as mild cognitive impairment and dementia. Stress indices (e.g., illness apprehension, pain sensitivity) and treatment prognostic factors (e.g., medication abuse, utilization excess) are rarely examined. Lifestyle factors, such as physical activity, smoking, drug abuse, alcohol and eating patterns are more widely assessed but still understudied at late life especially in the context of dementia. In recent years each of these variables has been found important in the care of older adults (Hyer, Molinari, Yeager, \& Mills, 2008). They may have important implications for case management and for targeted intervention.

The Millon Behavioral Medical Diagnostic (MBMD) is a personality measure that addresses many of the variables previously mentioned. The MBMD was developed as a personality inventory that addresses issues of physically ill people and medical-behavioral decision issues of importance. The MBMD has 165 items with 29 clinical scales. It is based on Millon's belief that personality-mediated coping styles are powerful influences on the genesis and course of illness. This scale has not been applied to older adults to any degree, but it is especially relevant for this group because of their high preponderance of medical problems. In the format of other Millon instruments, this test assesses personality patterns, as well as validity items, response patterns (Disclosure, Desirability, and Debasement), psychiatric factors, stress moderators that increase (e.g. spirituality) or decrease (e.g. lack of social supports), coping, factors that impact treatment prognostics, such as a tendency to abuse medications or poor compliance with physician orders, and lifestyle habits that have a negative effect on health, such as cigarette smoking. On the MBMD raw scores are transformed into prevalence scores which serve as the basis for selecting optimal cutting scores and insure that the proportions of various MBMD cut-off scores will be compatible to clinically judged indices found in diverse medical populations. For personality and psychiatric problems, elevations greater than 74 suggest that that variable asserts an influence on the person (presence), and with elevations greater than 84 , that the variable is prepotent in its influence (prominence). For Treatment Prognostics and Stress Moderators, scores are bidirectional. Low scores $(<\mathrm{PR} 36)$ reflect relative strengths and high scores $(>74)$ reflect relative problems.

Presently, we evaluate personality, depression and anxiety with a sample of adults who have come to a university-based Primary Care Clinic for memory problems. We first consider the differences on the MBMD in regards to personality, psychiatric problems, stress moderators, treatment prognostics, as well as life style. Specifically, we present profiles for dementia and nondementia but memory complaining groups. We then look at older adults with either depression or anxiety and diagnosed with dementia. We assess whether or not the addition of these mood states result in differing profiles.

\section{Experimental Procedures}

We collected data on a sample of older adults who came to a university-based Primary Care Clinic in the past few years. Patients had subjective memory complaints or other medical problems. In total, there were 224 individuals who were referred for neuropsychological assessment. Subjects were further disaggregated by dementia and non-dementia status as well as completion of all scales. There were 112 of these subjects. After this, we separated participants into those with a dementia, those 
who are normal (but had memory complaints), and those with both dementia and depression. The number for these more strict criteria was 62 (see below).

All patients were assessed with the Repeatable Battery for the Assessment of Neuropsychological Status (RBANS), Mini Mental State Exam (MMSE), the MBMD, as well as the Beck Depression Inventory (BDI-II), and the Short Anxiety Screening Test (SAST). All measures were scored as usual. For the MBMD we coded lifestyle markers as no problem (1), slight problem (2), or current problem (3). Internal reliability for the BDI-II was .88, GDS-SF was .92, and for the SAST was .89.

Dementia was defined as scores less than 20 on the MMSE and a RBANS Delayed Memory score less than 2 standard deviations low. This translates into zero or one word only recall on the List Learning subtest, less than 5 of the 12 story segments on the Story Recall subtest, and less than 8 of 20 portions of the complete figure on the Figure Memory subtest. This created two initial groups, Dementia and Normal. We later defined depression as a score greater than 12 on the BDI-II (Hyer, Molinari, Mills, \& Yeager, 2008). This provided us with three general groups, Dementia (no depression but positive for dementia), Depressed (no dementia but depressed), and Demented and Depressed (both dementia and depression). Groups were then assessed on the outcome measure-the MBMD. Participants were also given the Charlson Comorbidity Index to assess the general state of their comorbid conditions. This, along with other participant demographic information is presented in Table 1 .

Table 1: Demographic Information

\begin{tabular}{lll}
\hline Demographic & & $\begin{array}{l}\text { Mean/ Percent } \\
(\%)\end{array}$ \\
\hline Age & & 62.2 \\
Medications & & 4.6 \\
Charlson & & 2.4 \\
Gender & Male & $40.6 \%$ \\
& Female & $59.4 \%$ \\
Race & White & $80.2 \%$ \\
& Black & $19.0 \%$ \\
Marital & Other & $0.9 \%$ \\
Status & Single & $10.1 \%$ \\
& Married & $77.9 \%$ \\
& Widowed & $12.0 \%$ \\
Education & No High & $19.6 \%$ \\
& School & \\
& High School & $45.8 \%$ \\
& Some College & $10.2 \%$ \\
& College & $20 \%$ \\
& Post Grad & $4.4 \%$ \\
\hline
\end{tabular}

We conducted three sets of analyses. First, we performed simple t-tests on the MBMD and related variables for older individuals with and without dementia. We then calculated an ANOVA on the three groups, Dementia, Depressed and Dementia/Depressed (Both). We also provide a profile of each personality regarding treatment prognostics and stress moderators for both the Dementia and Depressed groups separately and then for the Dementia, Depressed, and Dementia/Depressed groups.

\section{Results}

Table 2 provides information on the personality profiles for the two groups, Dementia and Normal. Base rates for individuals being classified into each given category are also provided (PR >74). Significant differences were found in Introversive and Inhibited personality traits only. The Dementia group then was more detached. In addition, the Dementia group had all-but-one personality styles greater than Prevalence Rate 74 indicating more fixity in personality. In Table 3 we see some differences for psychiatric indicators and treatment prognostics. Regarding the Axis I problems, the Dementia group had significantly more concerns for Depression and Cognitive Dysfunction. In the Treatment Prognostic domain a significant difference between groups was demonstrated for only the Informational Fragility scale with the Dementia group scoring higher. No significant differences were found for any of the Stress Moderators. 
Table 2: Comparison of Coping Styles between the Dementia and Non-Dementia Groups

\begin{tabular}{|c|c|c|c|c|c|}
\hline Section & Measure & Cognitive Status & Number & Mean & $\%$ PR $>74$ \\
\hline \multirow{22}{*}{ Coping Styles } & \multirow{2}{*}{ Introversive* } & Dementia & 35 & 66.6 & 34 \\
\hline & & Non-Dementia & 67 & 53.4 & 22 \\
\hline & \multirow[t]{2}{*}{ Inhibited* } & Dementia & 35 & 60.0 & 23 \\
\hline & & Non-Dementia & 67 & 48.3 & 18 \\
\hline & \multirow[t]{2}{*}{ Dejected } & Dementia & 35 & 40.9 & 32 \\
\hline & & Non-Dementia & 67 & 35.7 & 24 \\
\hline & \multirow[t]{2}{*}{ Cooperative } & Dementia & 35 & 66.5 & 45 \\
\hline & & Non-Dementia & 67 & 59.3 & 36 \\
\hline & \multirow[t]{2}{*}{ Sociable } & Dementia & 35 & 42.2 & 6 \\
\hline & & Non-Dementia & 67 & 45.9 & 4 \\
\hline & \multirow[t]{2}{*}{ Confident } & Dementia & 35 & 39.4 & 11 \\
\hline & & Non-Dementia & 67 & 46.3 & 9 \\
\hline & \multirow[t]{2}{*}{ Nonconforming } & Dementia & 35 & 37.5 & 0 \\
\hline & & Non-Dementia & 67 & 35.8 & 1 \\
\hline & \multirow[t]{2}{*}{ Forceful } & Dementia & 35 & 33.0 & 29 \\
\hline & & Non-Dementia & 67 & 31.1 & 22 \\
\hline & \multirow[t]{2}{*}{ Respectful } & Dementia & 35 & 55.9 & 29 \\
\hline & & Non-Dementia & 67 & 56.7 & 22 \\
\hline & \multirow[t]{2}{*}{ Oppositional } & Dementia & 35 & 59.1 & 14 \\
\hline & & Non-Dementia & 67 & 52.8 & 13 \\
\hline & \multirow{2}{*}{ Denigrated } & Dementia & 35 & 59.2 & 20 \\
\hline & & Non-Dementia & 67 & 48.9 & 19 \\
\hline
\end{tabular}

*Significant at the .05 level

$\mathrm{PR}=$ Prevalence Rate

Table 3: Comparison of Other MBMD Variables between the Dementia and Non-Dementia Groups (*Significant at the .05 level)

\begin{tabular}{|c|c|c|c|c|}
\hline Section & Measure & Cognitive Status & Number & Mean \\
\hline Psychiatric & Anxiety Tension & Dementia & 35 & 62.0 \\
\hline \multirow[t]{9}{*}{ Indicators } & & Non-Dementia & 67 & 53.4 \\
\hline & Depression* & Dementia & 35 & 69.5 \\
\hline & & Non-Dementia & 67 & 56.3 \\
\hline & Cognitive Dysfunction* & Dementia & 35 & 66.5 \\
\hline & & Non-Dementia & 67 & 53.7 \\
\hline & Emotional Liability & Dementia & 35 & 47.8 \\
\hline & & Non-Dementia & 67 & 43.0 \\
\hline & Guardedness & Dementia & 35 & 46.7 \\
\hline & & Non-Dementia & 67 & 42.8 \\
\hline \multirow{12}{*}{ Stress Moderators } & Illness Apprehension & Dementia & 35 & 64.9 \\
\hline & & Non-Dementia & 67 & 61.2 \\
\hline & Functional Deficits & Dementia & 35 & 73.7 \\
\hline & & Non-Dementia & 67 & 71.5 \\
\hline & Pain Sensitivity & Dementia & 35 & 74.3 \\
\hline & & Non-Dementia & 67 & 68.6 \\
\hline & Social Isolation & Dementia & 35 & 57.1 \\
\hline & & Non-Dementia & 67 & 50.9 \\
\hline & Future Pessimism & Dementia & 35 & 67.8 \\
\hline & & Non-Dementia & 67 & 63.1 \\
\hline & Spiritual Absence & Dementia & 35 & 32.3 \\
\hline & & Non-Dementia & 67 & 25.0 \\
\hline \multirow{10}{*}{$\begin{array}{l}\text { Treatment } \\
\text { Prognostics }\end{array}$} & Interventional Fragility* & Dementia & 35 & 59.5 \\
\hline & & Non-Dementia & 67 & 47.4 \\
\hline & Medication Abuse & Dementia & 35 & 48.8 \\
\hline & & Non-Dementia & 67 & 41.6 \\
\hline & Information Discomfort & Dementia & 35 & 35.8 \\
\hline & & Non-Dementia & 67 & 31.3 \\
\hline & Utilization Excess & Dementia & 35 & 57.3 \\
\hline & & Non-Dementia & 67 & 49.0 \\
\hline & Problematic Compliance & Dementia & 35 & 51.7 \\
\hline & & Non-Dementia & 67 & 53.3 \\
\hline
\end{tabular}


Our second focus was on assessing the impact of comorbid depression, as well as dementia or depression alone. Regarding personality styles, the detached personality styles, as well as the Cooperative scale, showed significant differences (Table 4). Again, base rates for individuals being classified into each given category are also provided here with considerable variability among the groups. For the other variables (Table 5), analysis of the Psychiatric Indicators domain revealed that three of the scales had significant differences among Dementia, Depressed, and Dementia/Depression groups. In each case the Dementia/Depression group, as well as the Depression group, had more problems than the Dementia group alone. Regarding Stress Moderators, Illness Apprehension, Functional Deficits, and Pain Sensitivity scales were found to be significantly different among the groups, again with the Dementia/Depression group and Depression group as different from the Dementia group. In the Treatment Prognostics domain Informational Fragility was found to be significant, this time in favor of the Dementia/Depression group.

Table 4: Comparison of Coping Styles between the Dementia, Depression, and Demented/Depressed Groups

\begin{tabular}{|c|c|c|c|c|c|}
\hline Section & Measure & Cognitive Status & Number & Mean & $\%$ PR $>74$ \\
\hline \multirow[t]{30}{*}{ Coping Styles } & Introversive* & Dementia & 21 & 64.7 & 28 \\
\hline & & Depression & 7 & 62.1 & 28 \\
\hline & & Both & 13 & 82.8 & 62 \\
\hline & Inhibited* & Dementia & 21 & 63.7 & 28 \\
\hline & & Depression & 7 & 55.9 & 14 \\
\hline & & Both & 13 & 71.8 & 26 \\
\hline & Dejected & Dementia & 21 & 62.7 & 52 \\
\hline & & Depression & 7 & 29.1 & 28 \\
\hline & & Both & 13 & 61.3 & 54 \\
\hline & Cooperative* & Dementia & 21 & 72.8 .5 & 52 \\
\hline & & Depression & 7 & 56.0 & 28 \\
\hline & & Both & 13 & 80.4 & 62 \\
\hline & Sociable & Dementia & 21 & 34.5 & 0 \\
\hline & & Depression & 7 & 43.6 & 0 \\
\hline & Confident & Dementia & 21 & 35.9 & 0 \\
\hline & & Depression & 7 & 44.3 & 14 \\
\hline & & Both & 13 & 21.7 & 2 \\
\hline & Nonconforming & Dementia & 21 & 45.8 & 4 \\
\hline & & Depression & 7 & 31.6 & 0 \\
\hline & & Both & 13 & 46.9 & 0 \\
\hline & Forceful & Dementia & 21 & 37.5 & 0 \\
\hline & & Depression & 7 & 28.6 & 0 \\
\hline & & Both & 13 & 38.4 & 0 \\
\hline & Respectful & Dementia & 21 & 50.5 & 28 \\
\hline & & Depression & 7 & 56.4 & 14 \\
\hline & & Both & 13 & 44.2 & 23 \\
\hline & Oppositional & Dementia & 21 & 64.9 & 28 \\
\hline & & Depression & 7 & 52.4 & 0 \\
\hline & & Depression & 7 & 55.1 & 14 \\
\hline & & Both & 13 & 68.6 & 31 \\
\hline
\end{tabular}


Table 5: Comparison of Other MBMD Variables between the Dementia, Depression, and Demented/Depressed Groups

\begin{tabular}{|c|c|c|c|c|}
\hline Section & Measure & Cognitive Status & Number & Mean \\
\hline \multirow{15}{*}{$\begin{array}{l}\text { Psychiatric } \\
\text { Indicators }\end{array}$} & \multirow{3}{*}{ Anxiety Tension*** } & Dementia & 28 & 43.6 \\
\hline & & Depression & 13 & 79.9 \\
\hline & & Both & 21 & 63.1 \\
\hline & \multirow[t]{3}{*}{ Depression $* * *$} & Dementia & 28 & 43.0 \\
\hline & & Depression & 13 & 81.2 \\
\hline & & Both & 21 & 73.7 \\
\hline & \multirow[t]{3}{*}{ Cognitive Dysfunction $* * *$} & Dementia & 28 & 46.0 \\
\hline & & Depression & 13 & 76.0 \\
\hline & & Both & 21 & 60.8 \\
\hline & \multirow{3}{*}{ Emotional Lability*** } & Dementia & 28 & 36.1 \\
\hline & & Depression & 13 & 55.8 \\
\hline & & Both & 21 & 50.9 \\
\hline & \multirow[t]{3}{*}{ Guardedness* } & Dementia & 28 & 37.5 \\
\hline & & Depression & 13 & 45.0 \\
\hline & & Both & 21 & 49.9 \\
\hline \multirow{18}{*}{ Stress Moderators } & \multirow{3}{*}{ Illness Apprehension* } & Dementia & 21 & 71.4 \\
\hline & & Depression & 7 & 53.1 \\
\hline & & Both & 13 & 77.1 \\
\hline & \multirow{3}{*}{ Functional Deficits* } & Dementia & 21 & 83.6 \\
\hline & & Depression & 7 & 61.0 \\
\hline & & Both & 13 & 92.2 \\
\hline & \multirow[t]{3}{*}{ Pain Sensitivity* } & Dementia & 21 & 83.3 \\
\hline & & Depression & 7 & 61.1 \\
\hline & & Both & 13 & 92.5 \\
\hline & \multirow{3}{*}{ Social Isolation } & Dementia & 21 & 61.0 \\
\hline & & Depression & 7 & 65.0 \\
\hline & & Both & 13 & 60.0 \\
\hline & \multirow[t]{3}{*}{ Future Pessimism } & Dementia & 21 & 72.4 \\
\hline & & Depression & 7 & 62.2 \\
\hline & & Both & 13 & 75.8 \\
\hline & \multirow{3}{*}{ Spiritual Absence } & Dementia & 21 & 23.2 \\
\hline & & Depression & 7 & 19.4 \\
\hline & & Both & 13 & 28.4 \\
\hline \multirow{15}{*}{$\begin{array}{l}\text { Treatment } \\
\text { Prognostics }\end{array}$} & \multirow[t]{3}{*}{ Interventional Fragility* } & Dementia & 21 & 50.3 \\
\hline & & Depression & 7 & 48.3 \\
\hline & & Both & 13 & 72.5 \\
\hline & \multirow[t]{3}{*}{ Medication Abuse } & Dementia & 21 & 44.3 \\
\hline & & Depression & 7 & 43.7 \\
\hline & & Both & 13 & 47.8 \\
\hline & \multirow[t]{3}{*}{ Information Discomfort } & Dementia & 21 & 26.0 \\
\hline & & Depression & 7 & 25.7 \\
\hline & & Both & 13 & 32.7 \\
\hline & \multirow[t]{3}{*}{ Utilization Excess } & Dementia & 21 & 61.4 \\
\hline & & Depression & 7 & 50.4 \\
\hline & & Both & 13 & 67.4 \\
\hline & \multirow{3}{*}{ Problematic Compliance } & Dementia & 21 & 54.7 \\
\hline & & Depression & 7 & 63.1 \\
\hline & & Both & 13 & 47.5 \\
\hline
\end{tabular}

*Significant at the .05 level

The personality profiles are also noteworthy. Figure 1 gives a profile of mean scores of individuals with elevated levels of MBMD coping styles (PR> 74) on each treatment prognostic for dementia. This figure demonstrates graphically the behavior of an average individual with dementia and levels of any treatment or stress marker. Likewise, Figure 2 gives the same plot for the group with both dementia and depression. As before, this figure demonstrates the expected behavior of an average individual. 


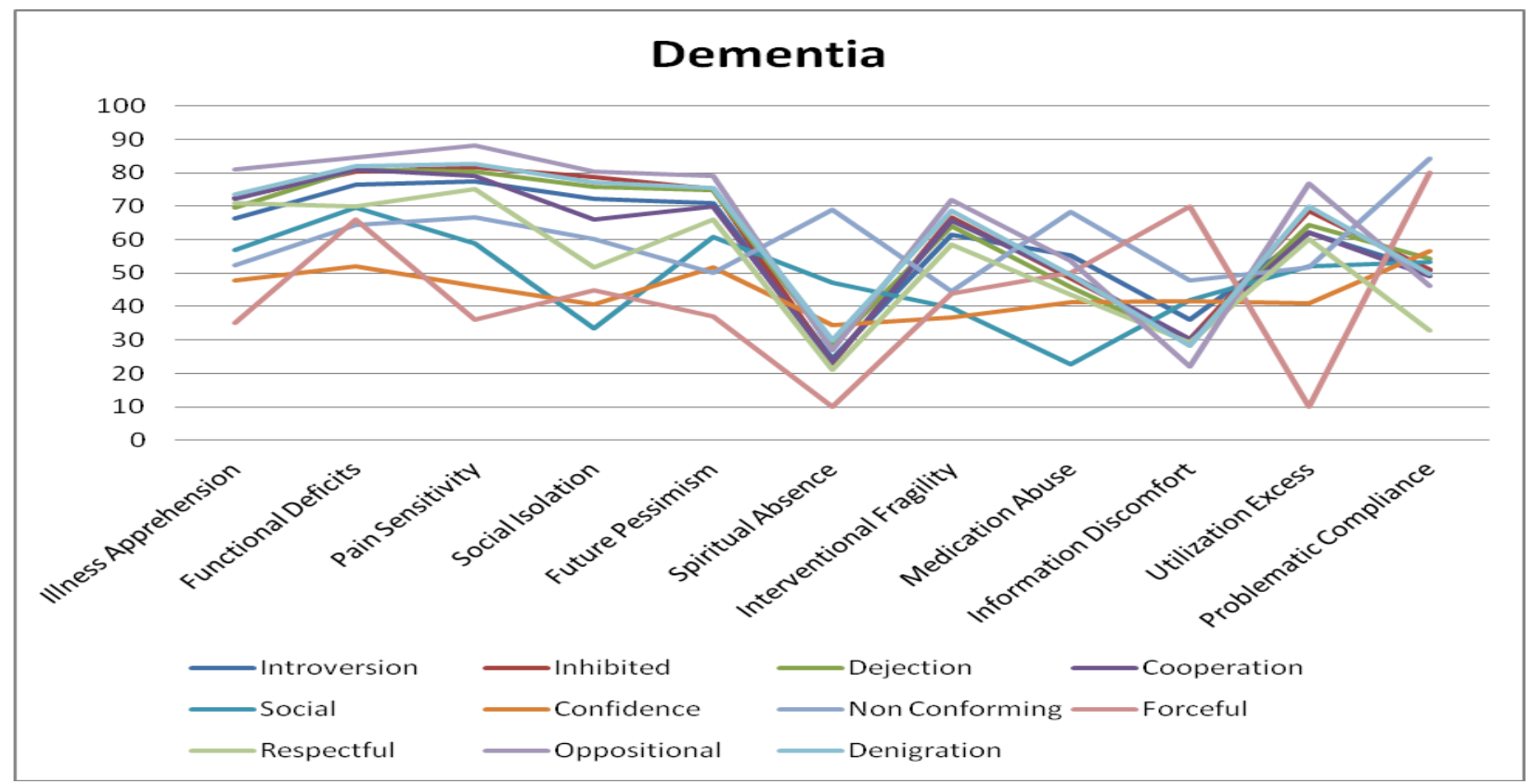

Figure 1: Personality Profiles for Dementia on Treatment Prognostics and Stress Moderators

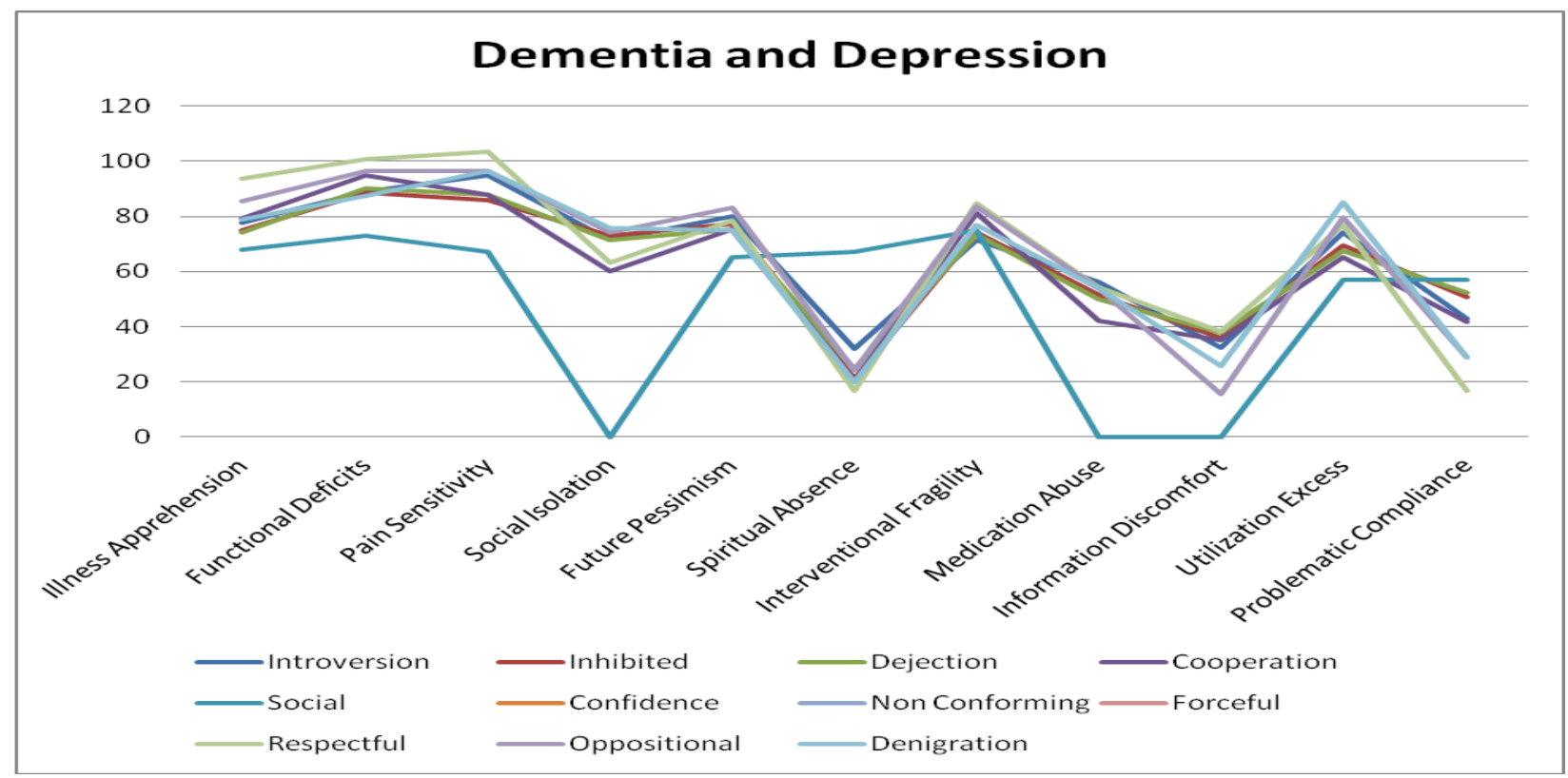

Figure 2: Personality Profiles for Dementia and Depression for Treatment Prognostics and Stress Moderators

\section{Discussion}

This is one of the few studies that addresses personality in the context of dementia as well as depression and considers treatment and stress components. Based on a community sample of memory complaining subjects, several patients were found to be dementing, depressed, or both. We also had normal subjects. When we looked at just the two groups, dementia and normal, we found that the dementia group was more detached (Introversive and Inhibited). This is predictable as those with a dementia begin to become more isolative and private. Whether this represents a long-standing personality feature or is a result of the degenerative process is unknown. For psychiatric problems, again results made sense, as the dementia group had more concerns about depression and cognitive dysfunction. This group is then more saddened and concerned about their cognitive status. Interestingly, only 
for the Treatment Prognostic domain of Informational Fragility was there a difference between the groups, in favor of the Dementia group. This indicates that this impaired group presented with memory complaints and was aware of possible problems. No significant differences were found for any of the Stress Moderators.

When the three groups were evaluated, there was variability. In general, depression was an added problem but only if one was demented. We had expected that the combined group would have the most problems, including more negative personality features. Regarding personality styles, the Introversive and Inhibited as well as the Cooperative scales peaked as a difference. Those with Dementia/Depression generally had greater values but the pattern was closest for the Dementia and Dementia/Depression groups. While puzzling, this reflects a trend among dementing older adults who have more problems, especially if depressed. These were less in evidence if one was only depressed. Regarding psychiatric factors, both the Dementia/Depression and Demented groups revealed more difficulties than the Depression group. This trend followed for Stress Moderators as Illness Apprehension, Functional Deficits, and Pain Sensitivity were more problematic for the Dementia/Depression and Demented groups. In the Treatment Prognostics domain only Informational Fragility was found to be significant in favor of the Dementia/Depression group.

The personality profiles of treatment prognostics and stress moderators are also of interest, both for dementia and dementia with depression. The clinician can view the profiles of any personality type and see if problems are likely. It is clear from a quick comparison of the two different figures that personality profiles for treatment prognostics seem to differ more for patients with solely dementia than for those with both dementia and depression. Continued inquiry in this area may help to develop a better understanding of how different personalities are exhibited by patients when dementia or depression are factors.

This is a study in a clinical setting. It has limits. First, there were missing data among the groups. This could not be avoided and we took precautions to limit this. There were no noted differences between subjects without data compared to those with data. Also, the normal group decidely had subjects with mild cognitive impairment (MCI) even though we limited those subjects with more strict screens (normal groups did not meet clinical definition of MCI). Also, it may have occurred that some of the dementing subjects could not read as well, given a dementia. The MBMD demands a $5^{\text {th }}$ grade reading level. All subjects had a reading level beyond that. No subjects were considered in the moderate dementing stages based on the Clinical Dementia Rating. We did check with caregivers and were assured that the MBMD ratings were accurate. We note here too that the information for this study was the result of one scale- the MBMD. This is a limitation as the factor structure of the MBMD may influence the Base Rates of some of the scales with higher intercorrelations. Finally, as with many studies of this sort, the sample size was wanting, as selected cells were small. This resulted in less power than required for differences to confess themselves. Future research then should give special care to sample size and assure sufficient power to definitively profile these difficulties.

In sum, the problem variable is dementia; clearly the addition of depression with dementia affects outcomes related to treatment. Depression alone is less of a problem. This seems to be a special difficulty that develops when Dementia and Depression are comorbid. Importantly, the MBMD is a simple scale that measures these variables. Little literature exists on these constructs even though they are clinically appealing. This is especially so with older adults.

\section{References}

Abrams, R. C., \& Horowitz, S. V. (1996). Personality disorders after age 50: A meta-analysis. Journal of Personality Disorders, 10, 271-281.

Alexopoulos, G. S., Meyers, B. S., Young, R. C., Campbell, S., Silbersweig, D., \& Charlson, M. (1997). Vascular depression hypothesis. Archives of General Psychiatry, 54(10), 915-922.

Alexopoulos, G. S., Meyers, B. S., Young, R. C., Hull, J., Sirey, J. A., \& Kakuma, T. (2000).

Executive dysfunction and risk for relapse and recurrence of geriatric depression.

Archives of General Psychiatry, 57, 285-290.

Alexopoulos, G., Kiosses, D., Heo, M., Murphy, C., Shanmugham, B., \& Gunning-Dixon, F. (2005). Executive dysfunction and the course of geriatric depression. Biological Psychiatry, 58(3), 204210

Arve, S., Tilvis, R. S., Lehtonen, A., Valvanne, J., \& Sairanen, S. (1999). Coexistence of lowered mood and cognitive impairment of elderly people in five birth cohorts. Aging (Milano), 11(2), 9095.

Baldwin, R. C., Anderson, D., Black, S., Evans, S., Jones, R., Wilson, K., Iliffe, S.; Faculty of Old Age Psychiatry Working Group, Royal College of Psychiatrists (2003). International Journal of Geriatric Psychiatry, 18(9), 829-838.

Banerjee, S., Hellier, J., Dewey, M., Romeo, R., Ballard, C., Baldwin, R., Bentham, P., Fox, C., Holmes, C., Katona, C., Knapp, M., Lawton, C., Lindesay, J., Livingston, G., McCrae, N., MonizCook, E., Murray, J., Nurock, S., Orrell, M., O'Brien, J., Poppe, M., Thomas, A., Walwyn, R., Wilson, K., \& Burns, A. (2011). Sertraline or mirtazapine for depression in dementia (HTASADD): A randomized, multicenter, doubleblind, placebo-controlled trial. Lancet, 378, 403411.

Blazer, D. (2003). Depression in late life: Review and commentary. The Journals of Gerontology Series A: Biological Sciences and Medical Sciences, 58(3), M249-M265.

Blazer, D., Hybels, C., Fillenbaum, G., \& Pieper, C. (2005). Predictors of antidepressant use among older adults: Have they changed over time? American Journal of Psychiatry, 162(4), 705710. 
Breteler, M. M., van Swieten, J. C., Bots, M. L., Grobbee, D. E., Claus, J. J., van den Hout, J. H., van Harskamp, F., Tanghe, H. L., de Jong, P. T., van Gijn, J., et al. (1994). Cerebral white matter lesions, vascular risk factors, and cognitive function in a population-based study: The Rotterdam Study. Neurology, 44(7), 1246-1252.

Charlson, M., \& Peterson, J. (2002). Medical comorbidity and late life depression: What is known and what are the unmet needs? Biological Psychiatry,52(3), 226-235.

Charney, D., Reynolds, C., Lewis, L., Lebowitz, B. D., Sunderland, T., Alexopoulos, G. S., Blazer, D. G., Katz, I. R., Meyers, B. S., Arean, P. A., Borson, S., Brown, C., Bruce, M. L., Callahan, C. M., Charlson, M. E., Conwell, Y., Cuthbert, B. N., Devanand, D. P., Gibson, M. J., Gottlieb, G. L., Krishnan, K. R., Laden, S. K., Lyketsos, C. G., Mulsant, B. H., Niederehe, G., Olin, J. T., Oslin, D. W., Pearson, J., Persky, T., Pollock, B. G., Raetzman, S., Reynolds, M., Salzman, C., Schulz, R., Schwenk, T. L., Scolnick, E., Unutzer, J., Weissman, M. M., Young, R. C.; Depression and Bipolar Support Alliance. (2003). Dperession and Bipolar Support Alliance consensus statement on the unmet needs in diagnosis and treatment of mood disorders in late life. Achrives of General Psychiatry, 60(7), 664672.

Chatterjee, A., Strauss, M. E., Smyth, K. A., \& Whitehouse, P. J. (1992). Personality changes in Alzheimer's disease. Archives of Neurology, 49, 486-491.

de Leeuw, F. E., de Groot, J. C., Achten, E., Oudkerk, M., Ramos, L. M. P., Heijboer, R., Hofman, A., Jolles, J., van Gijn, J., \& Breteler, M. M. B. (2001). Prevalence of cerebral white matter lesions in elderly people: A population based magnetic resonance imaging study. The Rotterdam Scan Study. Journal of Neurology, Neurosurgery, and Psychiatry, 70, 9-14.

de Vasconcelos Cunha, U. G., Lopes Rocha, F., Avila de Melo, R., Alves Valle, E., de Souza Neto, J. J., Mendes Brega, R., Magalhães Scoralick, F., Araújo Silva, S., Martins de Oliveira, F., da Costa Júnior, A. L., Faria Alves, V. X., \& Sakurai, E. (2007). A placebo-controlled double-blind randomized study of venlafaxine in the treatment of depression in dementia. Dementia and Geriatric Cognitive Disorders, 24(1), 36-41.

Finkel, S. I. (1998). The signs of the behavioural and psychological symptoms of dementia. Clinician 1998, 16(1), 33-42.

Goldman, L. S., Nielsen, N. H., \& Champion, H. C. (1999). Awareness, diagnosis, and treatment of depression. Journal of General Internal Medicine, 14(9), 569-580.

Gould, S. L., \& Hyer, L. (2005). Dementia and behavioral disturbance: Does premorbid personality really matter? Psychological Reports, 95(3), 10721078.
Harman, J. S., Brown, E. L., Have, T. T., Mulsant, B. H., Brown, G., \& Bruce, M. L. (2002). Primary care physicians attitude toward diagnosis and treatment of late-life depression. CNS Spectrums, 7(11), 784-790.

Hollon, S., Jarrett, R., Nierenberg, A., Thase, M., Trivedi, M., \& Rush, A. J. (2005). Psychotherapy and medication in the treatment of adult and geriatric depression: Which monotherapy or combined treatment? Journal of Clinical Psychiatry, 66(4), 455-468.

Hyer, L., \& Intieri, R. (2006). Geropsychological interventions in long-term care. New York: Springer Publishing Company.

Hyer, L., Molinari, V., Mills, W., \& Yeager, C. A. (2008). Personolgical assessment and treatment of older adults. In T. Millon \& C. Bloom (Eds.), The millon inventories: A practitioner's guide to personalized clinical assessment (2nd ed., pp. 296-326). New York, NY: The Guilford Press.

Jack, C. R., Jr., Albert, M. S., Knopman, D. S., McKhann, G. M., Sperling, R. A., Carrillo, M.

C., Thies, B., \& Phelps, C. H. (2011). Introduction to the recommendations from the National Institute on Aging and the Alzheimer's Association workgroup on diagnostic guidelines for Alzheimer's disease. Alzheimer's \& Dementia, 7(3), 257-262.

Jeste, D. V., Alexopoulos, G. S., Bartels, S. J., Cummings, J. L., Gallo, J. J., Gottlieb, G. L., Halpain, M. C., Palmer, B. W., Patterson, T. L., Reynolds, C. F., \& Lebowitz, B. D. (1999). Consensus statement on the upcoming crisis in geriatric mental health: Research agenda for the next two decades. Archvies of General Psychiatry, 56, 848-853.

Kalayam, B., \& Alexopoulos, G. S. (1999). Prefrontal dysfunction and treatment response in geriatric depression. Archives of General Psychiatry, 56(8), 713-718.

Lopez, O. L., Jagust, W. J., Dulberg, C., Becker, J. T., DeKosky, S. T., Fitzpatrick, A., Breitner, J., Lyketsos, C., Jones, B., Kawas, C., Carlson, M., \& Kuller, L. H. (2003). Risk factors for Mild Cognitive Impairment in the Cardiovascular Health Study Cognition Study. Archives of Neurology, 60(10), 1394-1399.

Lyketsos, C., \& Olin, J. (2002). Depression in Alzheimer's disease: Overview and treatment. Biological Psychiatry, 52(3), 243-252.

Lyketsos, C., DelCampo, L., Steinberg, M., Miles, Q., Steele, C. D., Munro, C., Baker, A., Sheppard, J. M. E., Frangakis, C., Brandt, J., \& Rabins, P. V. (2003). Treating depression in Alzheimer's disease: Efficacy and safety in sertraline therapy and the benefits of depression reduction. Archives of General Psychiatry, 60, 737-746.

Potter, G., Kittinger, J., Wagner, H. R., Steffens, D., \& Krishnan, K. R. R. (2004). Prefrontal neuropsychological predictors of treatment remission in late-life depression. Neuropsychopharmacology, 29(12), 2266-2271. 
Segal, D. L., Coolidge, F. L., \& Rosowsky, E. (2006). Personality Disorders and Older Adults: Diagnosis, Assessment, and Treatment. Hoboken, NJ: Wiley.

Sneed, J., Roose, S., Keilp, J., Krishnan, K. R. R., Alexopoulos, G., \& Sackeim, H. (2007). Response inhibition predicts poor antidepressant treatment response in very old depressed patients. American Journal of Geriatric Psychiatry, 15(7), 553-563.

Story, T., Potter, G., Attix, D., Welsh-Bohmer, K., \& Steffens, D. (2008). Neurocognitive correlates of response to treatment in late-life depression.
American Journal of Geriatric Psychiatry, 16(9), 752-759.

Tiemeier, H. (2003). Biological risk factors for late life depression. European Journal of Epidemiology, 18(8), 745-750.

Uebelacker, L., Wang, P., Berglund, P., \& Kessler, R. (2006). Clinical differences among patients treated for mental health problems in general medical and specialty mental health settings in the National Comorbidity Survey Replication. General Hospital Psychiatry, 28(5), 387-395. 